\title{
Nitric acid in the stratosphere based on Odin observations from 2001 to 2009 - Part 2: High-altitude polar enhancements
}

\author{
Y. J. Orsolini ${ }^{1}$, J. Urban ${ }^{2}$, and D. P. Murtagh ${ }^{2}$ \\ ${ }^{1}$ Norwegian Institute for Air Research, Kjeller, Norway \\ ${ }^{2}$ Chalmers University of Technology, Department of Radio and Space Science, Göteborg, Sweden
}

Received: 25 January 2008 - Published in Atmos. Chem. Phys. Discuss.: 26 May 2008

Revised: 6 April 2009 - Accepted: 19 August 2009 - Published: 23 September 2009

\begin{abstract}
The wintertime abundance of nitric acid $\left(\mathrm{HNO}_{3}\right)$ in the polar upper stratosphere displays a strong inter-annual variability, and is known to be strongly influenced by energetic particle precipitation (EPP), primarily by protons during solar proton events (SPEs), but also by precipitating auroral or relativistic electrons. We analyse a multi-year record (August 2001 to April 2009) of middle atmospheric $\mathrm{HNO}_{3}$ measurements by the Sub-Millimeter Radiometer instrument aboard the Odin satellite, with a focus on the polar upper stratosphere. SMR observations show clear evidence of two different types of polar high-altitude $\mathrm{HNO}_{3}$ enhancements linked to EPP. In the first type, referred to as direct enhancements by analogy with the EPP/NO $\mathrm{Ni}_{\mathrm{x}}$ direct effect, enhanced $\mathrm{HNO}_{3}$ mixing ratios are observed for a short period (1 week) after a SPE, upwards of a level typically in the mid-stratosphere. In a second type, referred to as indirect enhancements by analogy with the EPP/NO $\mathrm{N}_{\mathrm{x}}$ indirect effect, the descent of mesospheric air triggers a stronger and longerlasting enhancement. Each of the three major SPEs that occurred during the Northern Hemisphere autumn or winter, in November 2001, October-November 2003 and January 2005, are observed to lead to both direct and indirect $\mathrm{HNO}_{3}$ enhancements. On the other hand, indirect enhancements occur recurrently in winter, are stronger in the Southern Hemisphere, and are influenced by EPP at higher altitudes.
\end{abstract}

\section{Introduction}

Nitric acid $\left(\mathrm{HNO}_{3}\right)$ is a key minor constituent of the middle atmosphere, part of the odd nitrogen family $\left(\mathrm{NO}_{\mathrm{y}}\right)$, and a reservoir for the active nitrogen species $\left(\mathrm{NO}_{\mathrm{x}}\right)$, which provide a major ozone loss catalytic cycle in the middle and up-

Correspondence to: Y. J. Orsolini (orsolini@nilu.no) per stratosphere. Stratospheric $\mathrm{HNO}_{3}$ has been observed by means of ground-based, balloon, aircraft and satellite instrumentation. The most complete dataset to date has been provided by the Microwave Limb Sounder (MLS) instrument aboard Upper Atmosphere Research Satellite (Santee et al., 2004), albeit not in the upper stratosphere. Since July 2004, the EOS/MLS instrument also makes global observations of $\mathrm{HNO}_{3}$ that cover the mid and upper stratosphere (Santee et al., 2007). The infrared Michelson Interferometer for Passive Atmospheric Sounding (MIPAS) aboard the ENVISAT satellite has also been measuring $\mathrm{HNO}_{3}$ since July 2002 (Stiller et al., 2005), but following an interruption in 2004, observations have not been continuous.

The "Odin Sub-Millimetre Radiometer" (SMR) instrument provides a continous record of global $\mathrm{HNO}_{3}$ observations every third day since summer 2001. We present results from a multi-year record (August 2001 to April 2009) in a two-part article. Urban et al. (2009) describes the characteristics of the satellite retrievals and the climatology and variability in the lower stratosphere, neither of which are repeated here. Here, we focus on the polar upper stratospherelower mesosphere. Enhanced layers of $\mathrm{HNO}_{3}$ are commonly observed in winter at high altitudes in the polar regions, as revealed by ground-based (de Zafra and Smyshlaev, 2001) or satellite (Austin et al., 1986; Kawa et al., 1995; LopezPuertas et al., 2005b, hereafter LP05; Orsolini et al., 2005a, hereafter OR05; Stiller et al., 2005) observations. Exceptionally strong enhancements have been shown in connection with energetic particle precipitation (EPP) events or anomalous descent of mesospheric air, both of which provide an enhanced source of stratospheric $\mathrm{NO}_{\mathrm{x}}$. However, they have not been previously documented over so many years by a single satellite instrument. The aim of this paper is to show the high inter-annual variability of high-altitude $\mathrm{HNO}_{3}$ polar enhancements, especially in the aftermath of major solar proton events (SPEs). 


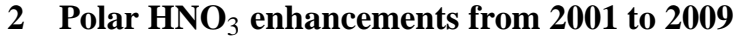

In the polar upper stratosphere in winter, $\mathrm{HNO}_{3}$ enhanced layers appeared recurrently in the Odin/SMR observation period considered here (2001-2009). In Fig. 1, the zonal-mean zonal wind at $1 \mathrm{hPa}$ and latitudes of $60^{\circ} \mathrm{N}$ or $60^{\circ} \mathrm{S}$ (top), the normalised solar radio flux at $10.7 \mathrm{~cm}$ (F10.7 index) and the daily A-p index of geomagnetic activity (middle), are shown to document the dynamical conditions in the polar upper stratosphere and the magnitude of solar-terrestrial coupling during that period. Winds are derived from operational analyses from the European Centre for Medium-Range Forecasting (ECMWF). Normalised intensities of GOES proton flux measurements are shown as indicators of SPEs (Fig. 1, middle), with Class-X SPEs highlighted. The period corresponds to the declining phase of the solar cycle as seen in the F10.7 index, and numerous, intense SPEs were observed (see also Jackman et al., 2008). SMR observations of $\mathrm{HNO}_{3}$ at a potential temperature level of $1600 \mathrm{~K}$ and at latitudes of $60^{\circ} \mathrm{N}$ or $60^{\circ} \mathrm{S}$ in Fig. 1 (bottom), or at $1400 \mathrm{~K}$ as a function of equivalent latitude in Fig. 2, reveal that, while recurrent, the amplitude of these winter polar enhancements varies widely from year to year in both hemispheres. The figures can be examined together with Figs. 2, 3 in Urban et al. (2009) which show the descent of the anomalies from the upper stratosphere. The largest enhancements in the $\mathrm{NH}$ follow the very strong SPEs in November 2001, in OctoberNovember 2003 (Halloween storms), and in January 2005. The SH also shows inter-annual variations, with the largest enhancement occurring in austral winter 2003.

Individual winters in each hemisphere from 2001 to 2007 are presented in Figs. 3 and 4, as time versus potential temperature cross-sections of $\mathrm{HNO}_{3}$ mixing ratio as well as mixing ratio anomalies from the winter mean, averaged over equivalent latitudes poleward of $70^{\circ}$. More recent winters have not been characterised by strong enhancements and are not shown. Occurrences of major Class-X SPEs are shown by pink circles with vertical lines. Enhancements appear recurrently in winter as air descending from the mesosphere always provides some amount of $\mathrm{NO}_{\mathrm{x}}$ and $\mathrm{HNO}_{3}$ conversion (de Zafra and Smyshlaev, 2001). Anomalously elevated stratospheric $\mathrm{NO}_{\mathrm{x}}$ abundances can hence arise from this downward transport, if EPP phenomena such as relativistic electron precipitation, or lower energy electron precipitation from auroral activity are strong or persistent, or SPEs occur. This is refered to as the EPP/NO ${ }_{\mathrm{x}}$ indirect effect (e.g., Randall et al., 2006). The efficiency of the mesosphere-tostratosphere transport depends upon meteorological conditions, which are quite variable, especially in the Northern Hemisphere. Stratospheric $\mathrm{NO}_{\mathrm{x}}$ abundances can also be amplified in-situ by most energetic EPP events, such as SPEs. This is refered to as the EPP/NO $/ \mathrm{x}_{\mathrm{x}}$ direct effect (e.g., Randall et al., 2006). EPP events have occasionally led to upperstratospheric $\mathrm{NO}_{2}$ abundances over a hundred ppb (Callis and Lambeth, 1998; OR05; LP05).

\section{Direct and indirect $\mathrm{HNO}_{3}$ enhancements following major SPEs}

SMR observations show clear evidence of two different types of $\mathrm{HNO}_{3}$ enhancements following the 3 major SPEs that occurred during the Northern Hemisphere autumn or winter over the Odin/SMR observation period considered here: November 2001, October-November 2003, and mid-January 2005. In a first type, enhancements are observed for a short period (1 week) upwards of a level typically in the midstratosphere, and are analogous to the EPP/NO $/ \mathrm{x}_{\mathrm{x}}$ direct effect. In a second type, the descent of mesospheric air triggers a stronger and longer-lasting enhancement, analogous to the $\mathrm{EPP} / \mathrm{NO}_{\mathrm{x}}$ indirect effect. In both cases though, $\mathrm{HNO}_{3}$ is mostly created in the stratosphere (unlike the $\mathrm{NO}_{\mathrm{x}}$ ).

A first example showing both direct and indirect enhancements follows the powerful November 2001 SPE: a shortlived (one week) layer of enhanced $\mathrm{HNO}_{3}$ appears above $1200 \mathrm{~K}$, extending upward into the upper stratosphere-lower mesosphere (at least $2000 \mathrm{~K}$ ). It is followed in December by a much stronger and longer-lasting descending enhancement, in fact the strongest anomaly in the SMR record for the NH. Probably the best studied SPEs were associated with the violent "Halloween" solar storms of autumn 2003. Both direct and indirect $\mathrm{HNO}_{3}$ enhancements were observed for the first time by MIPAS (LP05; OR05). Immediately following the SPE, a short-lived (about 1 week) stratospheric layer of enhanced $\mathrm{HNO}_{3}$, peaking at 2-2.5 ppb, was observed above $35 \mathrm{~km}$ by LP05. Newly reprocessed MIPAS retrievals indicate that the $\mathrm{HNO}_{3}$ enhancements extend into the upper stratosphere and lower mesosphere (Jackman et al., 2008). In the indirect enhancement, several weeks after the SPE, an anomalous $\mathrm{HNO}_{3}$-rich layer was first observed at about $45 \mathrm{~km}$ (OR05), and intensified considerably while descending confined in vortex air. By mid-January, it had reached $30 \mathrm{~km}$ and vortex-averaged $\mathrm{HNO}_{3}$ abundances were as high as $13-15 \mathrm{ppb}$, leading to double-peaked high-latitude $\mathrm{HNO}_{3}$ profiles. Vortex-averaged SMR measurements are in good agreement with those of MIPAS cited above. In individual SMR profiles, mixing ratios were as high as $7 \mathrm{ppb}$ at $40-45 \mathrm{~km}$ in early November 2004. A weaker direct $\mathrm{HNO}_{3}$ enhancement was also observed by MIPAS in the Southern Hemisphere following the SPEs (LP05). The corresponding enhancement is SMR is very weak, in the range of $1-2 \mathrm{ppb}$ at $40 \mathrm{~km}$ in individual profiles, not conclusively above the background levels.

Multiple $\mathrm{HNO}_{3}$ enhancements also appear during the winter 2004/2005. The indirect enhancement is starting early in December, while a direct enhancement coincides with the strong SPE of mid-January 2005, which ranked as number 11 of the last 4 decades (Jackman et al., 2007). However, the high fluxes for the most energetic protons $(>100 \mathrm{Mev})$, supported by calculation of ionisation rates (Verronen et al., 2005; Seppälä et al., 2008) indicate that the SPE penetrated as deep into the stratosphere as the Halloween 2003 event. 

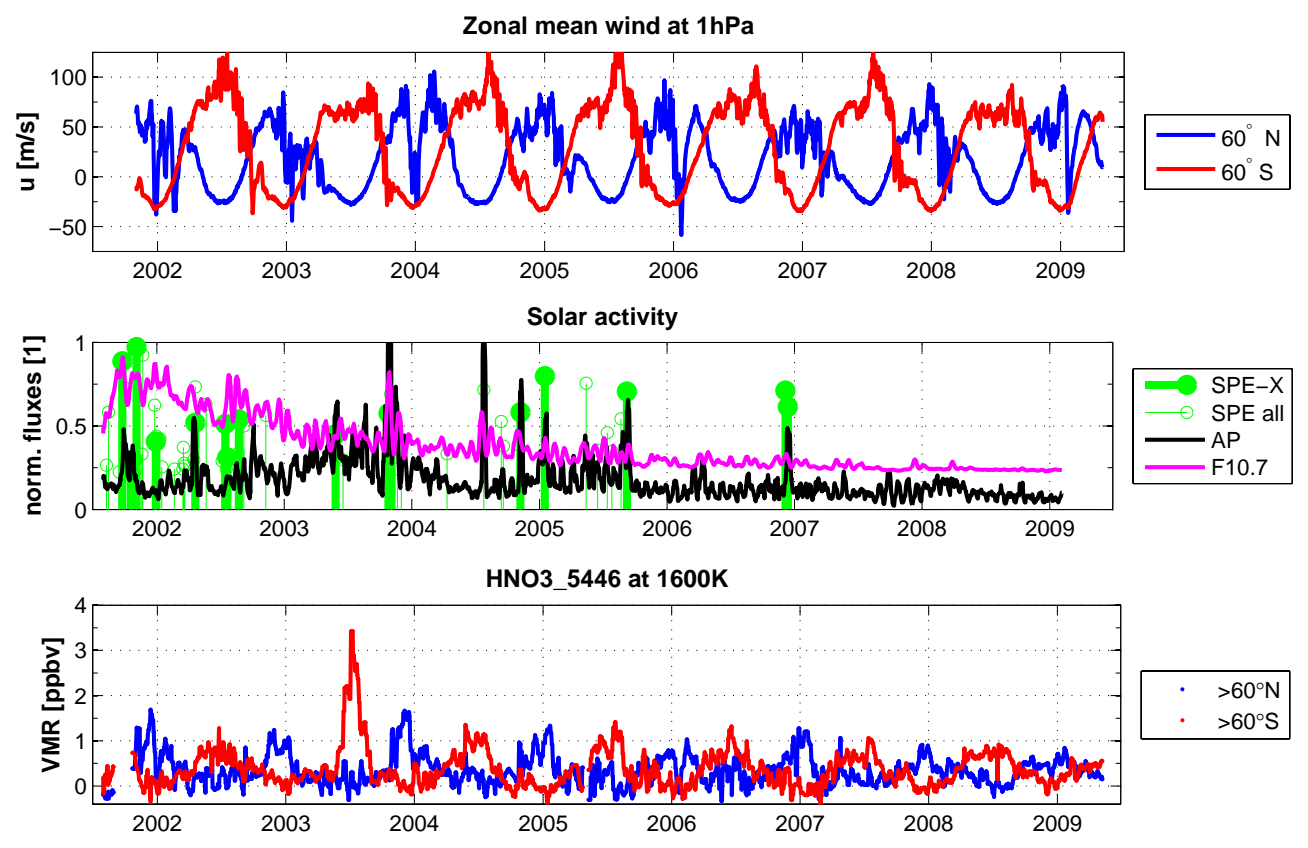

Fig. 1. (top) Zonal-mean zonal winds at $1 \mathrm{hPa}$ and at latitudes of $60^{\circ} \mathrm{N}$ or $60^{\circ} \mathrm{S}$, derived from ECMWF operational analyses. (middle) Normalised solar radio flux at $10.7 \mathrm{~cm}$, A-p index of geomagnetic activity, and normalised proton flux for both major (Class-X) as well as minor SPEs. (bottom) $\mathrm{HNO}_{3}$ mixing ratio (ppb) at a potential temperature level of $1600 \mathrm{~K}$ and at equivalent latitudes poleward of $60^{\circ} \mathrm{N}$ or $60^{\circ} \mathrm{S}$. X-axis is time, from August 2001 to April 2009.

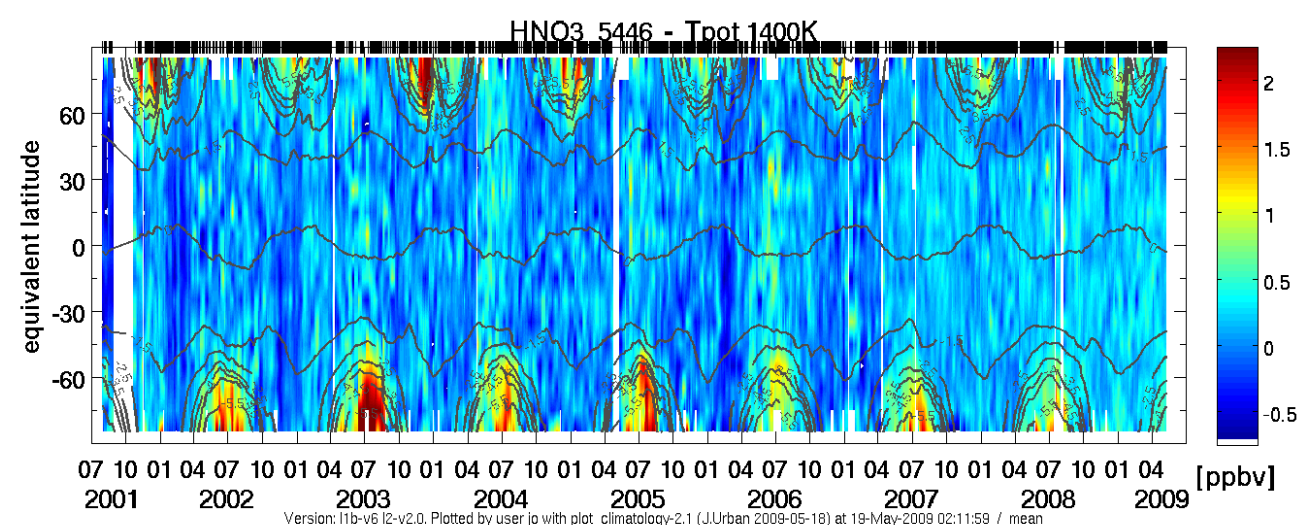

Fig. 2. Time vs. equivalent latitude $\mathrm{HNO}_{3}$ mixing (ppb) from August 2001 to April 2009, at a potential temperature of $1400 \mathrm{~K}$ (near $40 \mathrm{~km}$ ). Tick marks indicate the beginning of months.

The SMR observations indeed indicate $\mathrm{HNO}_{3}$ enhancements reaching lower levels, about $1000 \mathrm{~K}$, than during the Halloween 2003 event, and being in the $10-15 \mathrm{ppb}$ range at $30 \mathrm{~km}$ in early January. High carbon monoxide (CO) abundance can also be used to infer the descent of lower mesospheric air into the stratosphere, and vortex-averaged MLS observations already show a separated peak in $\mathrm{CO}$ at the $1400 \mathrm{~K}$ by mid-December (Manney et al., 2007). Hence the SPE, and the direct enhancement, occurred after the winter descent, and the indirect enhancement, had already started.
The above-mentioned three cases are the clearest cases in the Northern Hemisphere, when both direct and indirect $\mathrm{HNO}_{3}$ enhancements are observed. In the autumn 2004, a much weaker, short-lived enhancement can also be seen after a SPE in November, extending upward of $1500 \mathrm{~K}$. The two SPEs of December 2006 gave rise to a direct enhancement with a maximum near $1300 \mathrm{~K}-1500 \mathrm{~K}$, but it was weak and did not extend upwards as in the three clearly defined cases mentioned above. The indirect enhancement maximised in midJanuary 2007. 


\section{- Northern Hemisphere -}
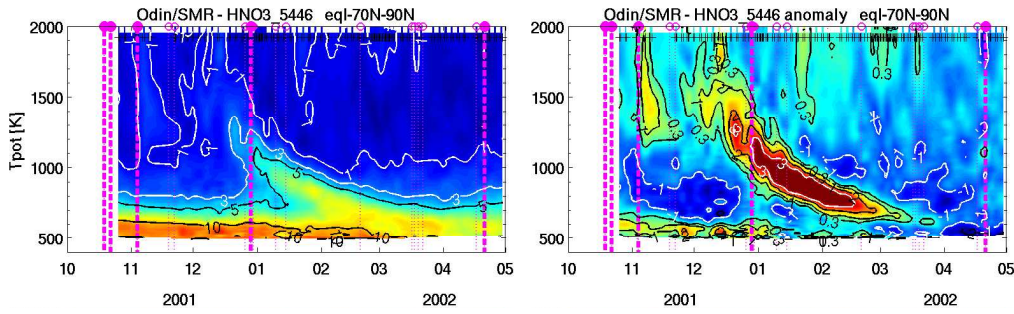

2001-02
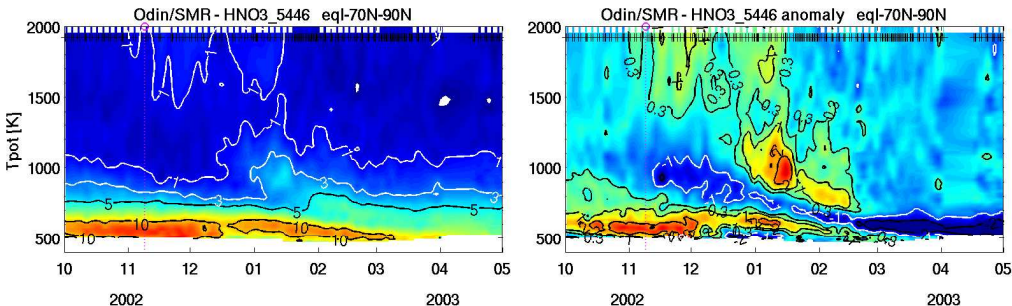

2002-03
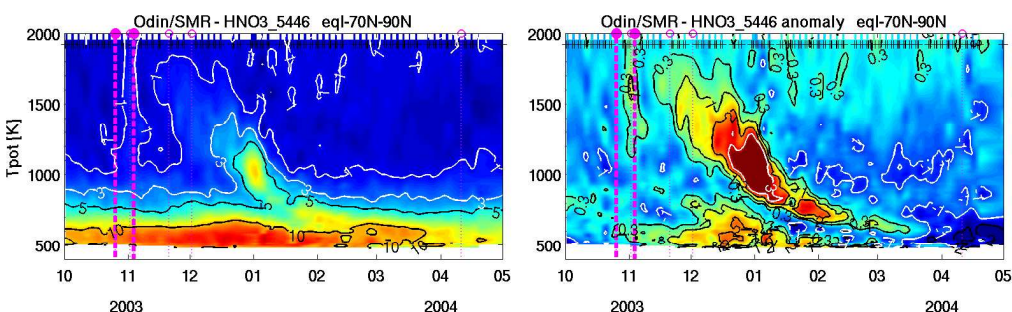

2003-04
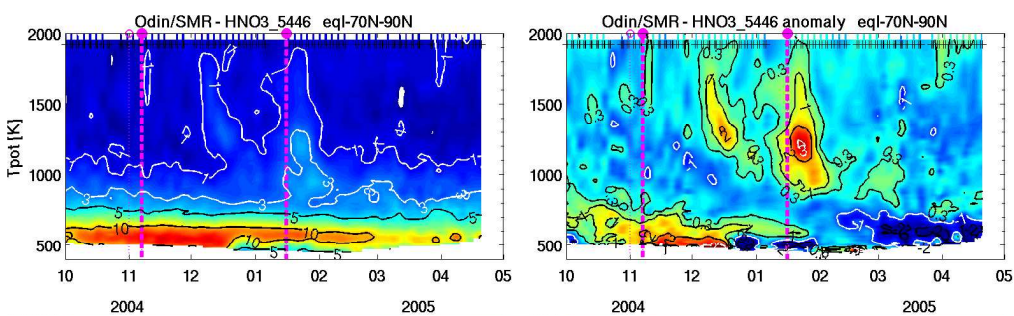

2004-05
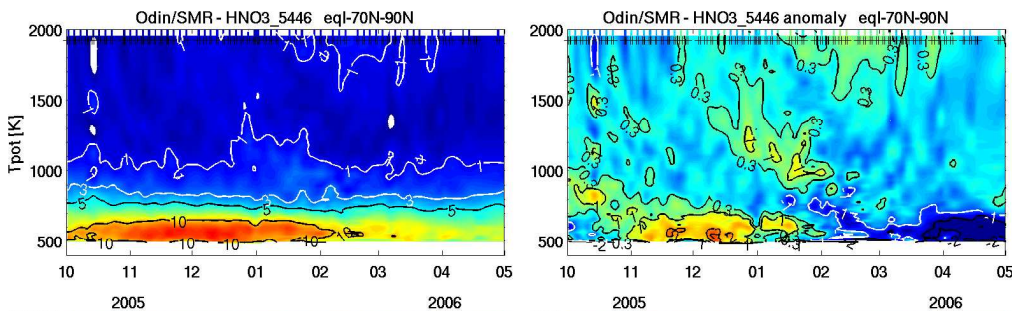

\section{5-06}
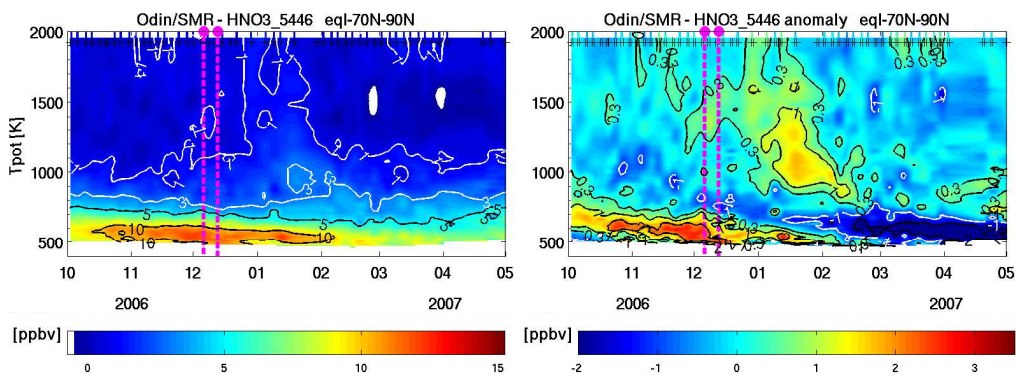

\section{6-07}

Fig. 3. Time vs. potential temperature evolution of vortex-averaged (equivalent latitudes $70^{\circ} \mathrm{N}-90^{\circ} \mathrm{N}$ ) $\mathrm{HNO}_{3}$ mixing ratio (ppb) (left column) and deviations from the winter mean (i.e. anomalies, right column), during NH winters 2001/2002 through 2006/2007. X-axis is labelled with months. Major, class X SPEs are indicated by pink circles with vertical lines. 


\section{Discussion}

The time development of the $\mathrm{HNO}_{3}$ anomalies involves the interplay of middle atmospheric dynamics and chemistry, and solar-terrestrial coupling. Two chemical pathways have been suggested in $\mathrm{LP} 05$ to explain the direct $\mathrm{HNO}_{3}$ enhancements: either gas phase reactions of $\mathrm{NO}_{2}$ with $\mathrm{OH}$, both enhanced by the SPE, or else ion chemistry (Solomon et al., 1981). A recent ion chemistry model study by Verronen et al. (2008) indicates that abundances of $\mathrm{HNO}_{3}$ observed by MIPAS following the Halloween 2003 SPEs are largely consistent with production above $35 \mathrm{~km}$ resulting from ionion recombination between ion clusters. They showed that the latter mechanism dominated both the gas phase formation and the heterogeneous conversions of $\mathrm{N}_{2} \mathrm{O}_{5}$ into $\mathrm{HNO}_{3}$ upon hydrated ion clusters. Whether the short duration of the enhancement can be solely explained by chemistry or by a combination of transport and chemistry, requires further modelling studies.

Following earlier suggestions (Bohringer et al., 1993; Kawa et al., 1995), de Zafra and Smyshlaev (2001) estimated that such $\mathrm{N}_{2} \mathrm{O}_{5}$ heterogeneous conversions upon hydrated ion clusters were responsible for the enhancements they observed in ground-based microwave measurements at the South Pole. This is the likely mechanism for the indirect enhancements, although this conclusion awaits quantitative model results. Sulphate aerosols were also suggested to play a role below $35 \mathrm{~km}$ (Bekki et al., 1995). The indirect enhancements require a large downward flux of $\mathrm{NO}_{2}$ to generate $\mathrm{N}_{2} \mathrm{O}_{5}$, a process favoured by vortex confinement, hence explaining the stronger effect in the SH. The background abundance of hydrated ion clusters is thought to be generated by galactic cosmic rays. How EPP influences that background abundance is an open question.

While the $\mathrm{HNO}_{3}$ enhancements share some characteristics of the $\mathrm{NO}_{\mathrm{x}}$ enhancements, such as high-altitude origin, polar confinement and descent, the latter are not always followed by $\mathrm{HNO}_{3}$ enhancements. An enhanced descent from the mesosphere into the stratosphere well-confined by a strong vortex would be leading to a large $\mathrm{EPP} / \mathrm{NO}_{\mathrm{x}}$ indirect effect. Three such strong descent events have been observed to occur during the vortex recovery from the mid-winter stratospheric sudden warmings in 2004, 2006 and 2009 (Randall et al., 2005, 2006, and reference therein; Manney et al., 2009), or as revealed by inspection of zonal-mean zonal winds at $1 \mathrm{hPa}$ in Fig. 1. $\mathrm{NO}_{\mathrm{x}}$ enhancements have been shown during the 2004 and 2006 events (see above references). The EPP/NO ${ }_{x}$ indirect effect did not give rise to large $\mathrm{HNO}_{3}$ enhancements. This would be consistent with the ion cluster chemistry requiring darkness to build up $\mathrm{HNO}_{3}$, conditions which are not provided in late winter and spring. In fact, there is only a signature of a weak enhancement during the $\mathrm{NO}_{\mathrm{x}}$ descent in March-April 2006 at the highest levels measured by SMR. These $\mathrm{NO}_{\mathrm{x}}$ descents in 2004 and 2006 were nevertheless important for the upper stratospheric ozone bud- get, leading for example to nearly $60 \%$ ozone destruction at $45 \mathrm{~km}$ in spring 2004 (Natarajan et al., 2004; Randall et al., 2005). Hence, while the short-lived, direct $\mathrm{HNO}_{3}$ enhancements could be triggered by SPEs in any season, SPEs contribute to indirect enhancements only from late autumn to winter. Hence, the seasonal timing of EPP events largely constrain their impact on $\mathrm{HNO}_{3}$ enhancements. Another effect of stratospheric warmings is that they could dampen the $\mathrm{HNO}_{3}$ anomalies by bringing polar air to sunlit regions.

Polar $\mathrm{HNO}_{3}$ enhancements in the $\mathrm{SH}$ also display a strong inter-annual variability (Fig. 4). But, in the $\mathrm{SH}$, the vortex is less variable than in the $\mathrm{NH}$, and the variations in EPP is playing a key role in year-to-year variability of polar $\mathrm{NO}_{\mathrm{x}}$ (Randall et al., 2007) or $\mathrm{HNO}_{3}$ enhancements. The strongest enhancement is seen to occur in austral winter 2003, and was studied by Stiller et al. (2005) using MIPAS data. The vortexaveraged magnitude of about $7 \mathrm{ppbv}$ at $1400 \mathrm{~K}$ is in good agreement with MIPAS measurements. Stiller et al. (2005) concluded that the enhancement originated from strong descent of mesospheric air enriched in $\mathrm{NO}_{\mathrm{x}}$ by enhanced auroral activity. Indeed, Tanskanen et al. (2005) indicated a high occurrence of magnetic substorms and auroral activity in 2003. It can be noticed in Fig. 1 that the SH vortex was not the strongest in austral winter 2003.

In SMR observations over the SH, we do not observe any clear-cut case showing both direct and indirect enhancements following SPEs. There is however a series of weak shortlived enhancements throughout the austral winter 2002, including a pronounced one following the July 2002 SPE, extending upward of about $1200 \mathrm{~K}$. As shown by the zonalmean zonal wind in Fig. 1 (top), this winter was characterised by a large dynamical variability that led to the sudden stratospheric warming of late September 2002 (Allen et al., 2003; Orsolini et al., 2005b). As for the January 2005 event in the $\mathrm{NH}$, the direct July 2002 enhancement would have occurred after the winter descent had started. It is not possible to clearly disentangle the effects of dynamical variability and SPEs, without a detailed model study. In particular, it is not clear why only the second SPE in July 2002 led to an upward-extended structure, that is characteristic of direct enhancements.

Inspection of Figs. 3 and 4 (as well as Figs. 2, 3 in Urban et al., 2009) reveals that, in the Northern Hemisphere, the enhancements descending from the upper stratosphere merge with the main layer when the abundance is still high, as clearly seen during the two strongest episodes in 2002 and 2004. In the SH, on the contrary, the descending layer normally reaches the lower stratosphere when the main layer abundance has already decreased considerably due to polar stratospheric cloud formation, during which there is uptake of $\mathrm{HNO}_{3}$ from the gas phase. A further point to note is that, as the high-altitude layer descends, the mixing ratios increase down to a certain level, which is quite variable, indicating continued production. 


\section{- Southern Hemisphere -}
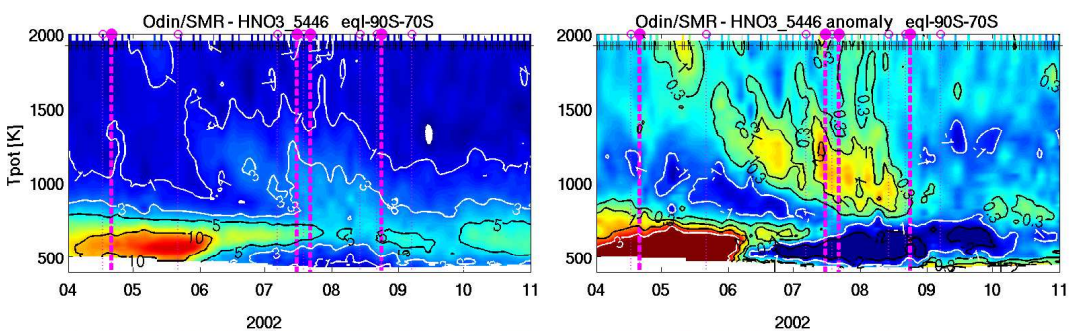

\section{2}
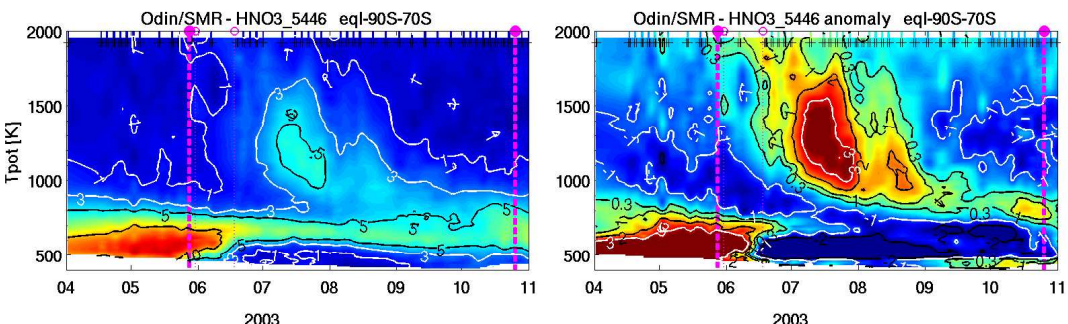

\section{3}
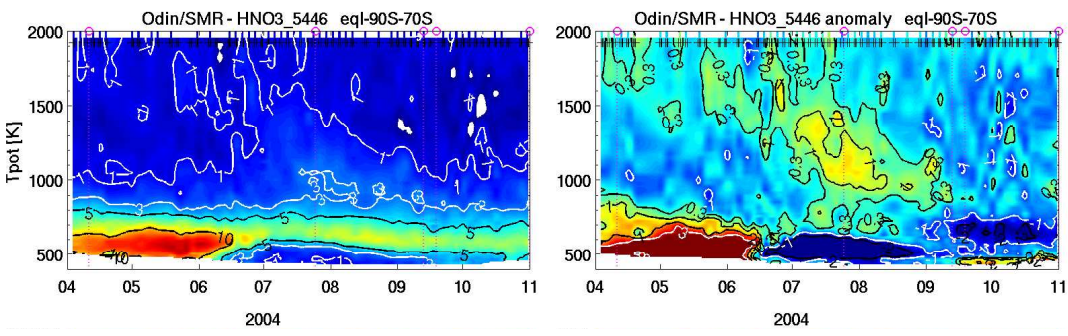

2004
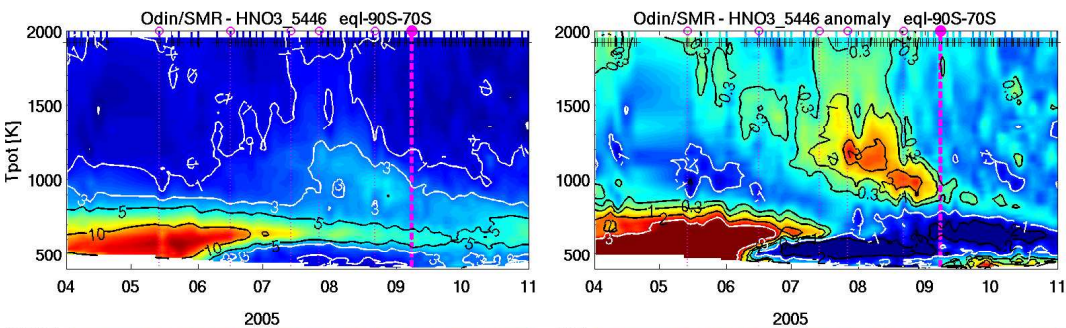

2005
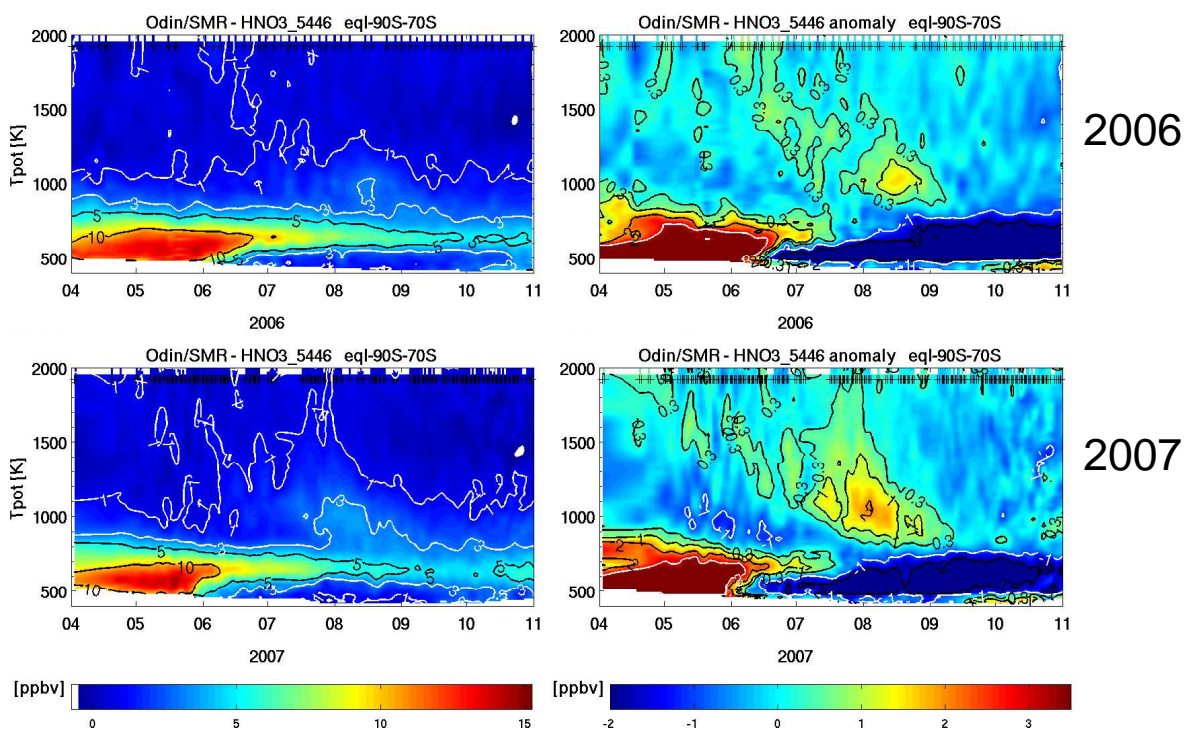

Fig. 4. Same as Fig. 2, for SH (equivalent latitudes $70^{\circ} \mathrm{S}-90^{\circ} \mathrm{S}$ ) winters 2002 through 2007. 


\section{Summary}

The Odin/SMR observations provide for the first time a multi-year record of polar $\mathrm{HNO}_{3}$ enhancements at high altitudes, and their downward propagation inside the winter polar vortex. Outstanding enhancements are seen during major SPEs or strong mesospheric descent events. Direct enhancements take the form of a short-lived (about 1 week) layer of enriched $\mathrm{HNO}_{3}$, extending from typically $35 \mathrm{~km}$ upwards into the upper stratosphere-lower mesosphere. The indirect enhancements are characterised by slowly-descending, larger anomalies, and are generally stronger in the Southern Hemisphere. Not all SPEs contribute to the indirect enhancements. Their effects depend not only of their intensity and penetration depth, but also on seasonal timing and meteorological conditions. On the other hand, indirect enhancements can occur without the occurrences of SPEs, and are influenced by EPP at higher altitudes. The occurrence of both direct and indirect $\mathrm{HNO}_{3}$ enhancements following a SPE was first observed by MIPAS (LP05; OR05) following the Halloween solar storms of autumn 2003, and is here confirmed by the SMR data in at least 2 additional cases.

The descending low or high $\mathrm{HNO}_{3}$ anomalies appear somewhat analogous to the tropical "tape-recorder" effect (Mote et al., 1996), that describes how low-latitude tracer anomalies imprinted at the tropopause level ascend over years, keeping a memory of their initial composition, and giving rise to layered anomalies in the tropical stratosphere. In this case, it is rather acting at high latitudes, and in reverse (propagating downwards) fashion, and on a faster (seasonal) scale: $\mathrm{HNO}_{3}$ anomalies are imprinted in the upper stratosphere, descending to the lower stratosphere over the course of the winter, and giving rise to a double-layered profile.

Further modelling studies are needed as a step toward implementing appropriate schemes to represent these processes affecting the stratospheric $\mathrm{NO}_{\mathrm{y}}$ budget into global chemical transport models.

Acknowledgements. Odin is a Swedish-led satellite project funded jointly by Sweden (SNSB), Canada (CSA), Finland (TEKES), France (CNES), and supported since 2007 by the third party mission programme of the European Space Agency (ESA). The lead author has been partially supported by the Norwegian Research Council.

Edited by: W. Ward

\section{References}

Allen, D. R., Bevilacqua, R. M., Nedoluha, G. E., et al: Unusual stratospheric transport and mixing during the 2002 Antarctic winter, Geophys. Res. Lett., 30, 1599, doi:10.1029/2003GL017117, 2003.

Austin, J., Garcia, R. R., Russell III, J. M., et al.: On the atmospheric photochemistry of nitric acid, J. Geophys. Res., 91, 5477-5485, 1986.
Bekki, S., Chipperfield, M. P., Pyle, J. A., Remedios, J. J., Smith, S. E., Grainger, R. G., Lambert, A., Kumer, J. B., and Mergenthaler, J. L.: Coupled aerosol-chemical modeling of UARS $\mathrm{HNO}_{3}$ and $\mathrm{N}_{2} \mathrm{O}_{5}$ measurements in the Arctic upper stratosphere, J. Geophys. Res., 102, 8977-8984, 1997.

Bohringer, H., Fahey, D. W., Fehsenfeld, F. C., and Ferguson, E. E.: The role of ion-molecule reactions in the conversion of $\mathrm{N}_{2} \mathrm{O}_{5}$ to $\mathrm{HNO}_{3}$ in the stratosphere, Planet. Space Sci., 31, 185-191, 1983.

Callis, L. and Lambeth, J. D.: $\mathrm{NO}_{\mathrm{y}}$ formed by precipitating electron events in 1991 and 1992: descent into the stratosphere as observed by ISAMS, Geophys. Res. Lett., 25, 1875-1878, 1998.

de Zafra, R. and Smyshlaev, S. P.: On the formation of $\mathrm{HNO}_{3}$ in the Antarctic mid to upper stratosphere in winter, J. Geophys. Res., 106, 23115-23125, 2001.

Jackman, C., Dowland, M. T., Labow, G. J., et al.: Neutral atmospheric influences of the solar proton events in October-November 2003, J. Geophys. Res., 110, A09S27, doi:10.1029/2004JA010888, 2005.

Jackman, C. H., Marsh, D. R., Vitt, F. M., Garcia, R. R., Fleming, E. L., Labow, G. J., Randall, C. E., López-Puertas, M., Funke, B., von Clarmann, T., and Stiller, G. P.: Short- and medium-term atmospheric constituent effects of very large solar proton events, Atmos. Chem. Phys., 8, 765-785, 2008, http://www.atmos-chem-phys.net/8/765/2008/.

Kawa, S. R., Kumer, J. B., Douglass, A. R., et al.: Missing chemistry of reactive nitrogen in the upper stratospheric polar winter, Geophys. Res. Lett., 22, 2629-2632, 1995.

Lopez-Puertas, M., Funke, B., Gil-Lopez, S., et al.: Observation of $\mathrm{NO}_{\mathrm{x}}$ enhancement and ozone depletion in the Northern and Southern Hemispheres after the October-November 2003 solar proton events, J. Geophys. Res., 110, A09S43, doi:10.1029/2005JA011050, 2005a.

Lopez-Puertas, M., Funke, B., Gil-Lopez, S., et al.: $\mathrm{HNO}_{3}$, $\mathrm{N}_{2} \mathrm{O}_{5}$ and $\mathrm{ClONO}_{2}$ enhancements after the October-November 2003 solar proton events, J. Geophys. Res., 110(A9), A09S44, doi:10.1029/2005JA011051, 2005b.

Manney, G. L., Daffer, W. H., Zawodny, J. M., et al.: Solar occultation satellite data and derived meteorological products: sampling issues and comparisons with AURA Microwave Limb Sounder, J. Geophys. Res., 112, D24S50, doi:10.1029/2007JD008709, 2007.

Manney, G. L., Schwartz, M. J., Krüger, K., Santee, M. L., Pawson, S., Lee, J. N., Daffer, W. H., Fuller, R. A., and Livesey, N. J.: Aura Microwave Limb Sounder observations of dynamics and transport during the record-breaking 2009 Arctic stratospheric major warming, Geophys. Res. Lett., 36, L12815, doi:10.1029/2009GL038586, 2009.

Mote, P. W., Rosenlof, K. H., McIntyre, M. E., et al.: An atmospheric tape recorder: The imprint of tropical tropopause temperatures on stratospheric water vapor, J. Geophys. Res., 101(D2), 3989-4006, 1996.

Natarajan, M., Remsberg, E. E., Deaver, L. E., and Russell III, J. M.: Anomalously high levels of $\mathrm{NO}_{\mathrm{x}}$ in the polar upper stratosphere during April, 2004: Photochemical consistency of HALOE observation, Geophys. Res. Lett., 31, L15113, doi:10.1029/2004GL020566, 2004.

Orsolini, Y. J., Manney, G. L., Santee, M., and Randall, C. E.: An upper stratospheric layer of enhanced $\mathrm{HNO}_{3}$ following exceptional solar storms, Geophys. Res. Lett., 32(12), L12S01, 
doi:10.1029/2004GL021588, 2005.

Orsolini, Y. J., Randall, C. E., Manney, G. L., and Allen, D.: An observational study of the final breakdown of the southern hemisphere stratospheric polar vortex in 2002, J. Atmos. Sci., 62, 735-747, 2005.

Randall, C. E., Harvey, V. L., and Manney, G. L.: Stratospheric effects of energetic particle precipitation in 2003-2004, Geophys. Res. Lett., 32, L05802, doi:10.1029/2004GL022003, 2005.

Randall, C.E., et al. Enhanced NOx in 2006 linked to strong upper stratospheric Arctic vortex, Geophys. Res. Lett., 33, L18811, doi:10.1029/2006GL027160, 2006.

Randall C. E., Harvey, V. L., Singleton, C. S., Bailey, S. M., Bernath, P. F., Codrescu, M., Nakajima, H., and Russell III, J. M.: Energetic particle precipitation effects on the Southern Hemisphere stratosphere in 1992-2005, J. Geophys. Res., 112, D08308, doi:10.1029/2006JD007696, 2007.

Santee, M., Manney, G. L., Livesey, N. J., Read, W. G., et al.: Three-dimensional structure and evolution of stratospheric $\mathrm{HNO}_{3}$ based on UARS Microwave Limb Sounder measurements, J. Geophys. Res., 109, D15306, doi:10.129/2004/JD004578, 2004.

Santee, M. L., Lambert, A., Read, W. G., Livesey, N. J., Cofield, R. E., Cuddy, D. T., Daffer, W. H., Drouin, B. J., Froidevaux, L., Fuller, R. A., Jarnot, R. F., Knosp, B. W., Manney, G. L., Perun, V. S., Snyder, W. V., Stek, P. C., Thurstans, R. P., Wagner, P. A., Waters, J. W., Muscari, G., deZafra, R. L., Dibb, J. E., Fahey, D. W., Popp, P. J., Marcy, T. P., Jucks, K. W., Toon, G. C., Stachnik, R. A., Bernath, P. F., Boone, C. D., Walker, K. A., Urban, J., and Murtagh, D.: Validation of Aura Microwave Limb Sounder $\mathrm{HNO}_{3}$ Measurements, J. Geophys. Res., 112, D24S40, doi:10.1029/2007JD008721, 2007.

Semeniuk, K, McConnell, J. C., and Jackman, C. H.: Simulation of the October-November 2003 solar proton event in the CMAM GCM: comparison with observations, Geophys. Res. Lett., 32, L15S02, doi:10.1029/2005GL022392, 2005.
Seppälä, A., Cliverd, M. A., Rodger, C. J., Verronen, P. T., and Turunen, E.: The effects of hard-spectra solar proton events on the middle atmosphere, J. Geophys. Res., 113, A11311, doi:10.1029/2008JA013517, 2008.

Solomon, S., Rusch, D. W., Gerard, J.-C., Reid, G. C., and Crutzen, P. J.: The effect of particle precipitation events on the neutral and ion chemistry of the middle atmosphere, II. Odd hydrogen, Planet. Space Sci., 29, 885-892, 1981.

Stiller, G., Tsidu, G. M., von Clarmann, T., et al.: An enhanced $\mathrm{HNO}_{3}$ second maximum in the Antarctic midwinter upper stratosphere in 2003, J. Geophys. Res., 110(D20), D20303, doi:10.1029/2005JD006011, 2005.

Tanskanen, E. I., Slavin, J. A., Tanskanen, A. J., et al.: Magnetospheric substorms are strongly modulated by interplanetary high-speed streams, Geophys. Res. Lett., 32, L16104, doi:10.1029/2005GL023318, 2005.

Urban, J., Pommier, M., Murtagh, D. P., Santee, M. L., and Orsolini, Y. J.: Nitric acid in the stratosphere based on Odin observations from 2001 to 2009 - Part 1: A global climatology, Atmos. Chem. Phys., 9, 7031-7044, 2009, http://www.atmos-chem-phys.net/9/7031/2009/.

Verronen, P. T., Seppälä, A., Cliverd, M. A., Rodger, C. J., Kyrölä, E., Enell, C.-F., Ulich, T., and Turunen, E.: Diurnal variation of ozone depletion during the October-November 2003 solar proton events, J. Geophys. Res., 110, A09S32, doi:10.1029/2004JA010932, 2005.

Verronen, P. T., Funke, B., Lopez-Puertas, M., Stiller, G. P., Von Clarmann, T., Glatthor, N., Enell, C.-F., Turunen, E., and Tamminen, J.: About the increase of $\mathrm{HNO}_{3}$ in the stratopause region during the Halloween 2003 solar proton event, Geophys. Res. Lett., 35, L20809, doi:10.1029/2008GL035312, 2008. 